\title{
The Effect of Bilateral Nephrectomy and Midcollicular De- cerebration with Pinealectomy and Hypophysectomy on the Corticosteroid Secretion of Sodium- deficient Sheep *
}

\author{
J. R. Blair-West, J. P. Coghlan, D. A. Denton, J. A. Munro, \\ Marelyn Wintour, and R. D. Wright
}

(From the Howard Florey Laboratories of Experimental Physiology, University of Melbourne, Parkville, N.2., Australia)

The adrenal gland, whether in its normal situation or transplanted to another site, responds to sodium depletion $(1,2)$, constriction of the inferior vena cava $(3)$, or hemorrhage $(3,4)$ by increased secretion of aldosterone. Crosscirculation studies of Denton, Goding, and Wright (1) and Yankopoulos, Davis, Kliman, and Peterson (5) indicate that the stimulus to the adrenal is humoral. Three local humoral circumstances, ACTH infusion (2, 6-8), angiotensin II infusion $(2,6,9-12)$, and low sodium and high potassium concentration of plasma $(1,2,6,13)$, are known to cause an increase in aldosterone secretion, and the levels required for the reaction are not beyond those that are known or might be presumed to occur naturally. However, conscious unstressed dogs with thoracic caval constriction showed a 20 - to 40-fold increase in aldosterone secretion rates associated with low corticosterone and Porter-Silber chromogen secretion (14). Experiments on conscious sheep with adrenal transplants have shown that with the development of sodium deficiency of 100 to $300 \mathrm{mEq}$, the aldosterone secretion may rise up to 10 -fold without change of cortisol and corticosterone from basal level (2). These experiments clearly demonstrate that in the conscious animal ACTH is not the factor directly causal of increased aldosterone production in response to the physiological stimulus. In the ex-

* Submitted for publication February 25, 1963; accepted April 17, 1964.

Supported by research grants from the U. S. Public Health Service, research grant H.6284 from the National Heart Institute, the National Health and Medical Research Council, the Anti-Cancer Council of Victoria, the Wool Research Fund of the Commonwealth, and the Rural Credits Fund of the Reserve Bank of Australia. periments studying the onset of sodium deficiency (2) and inferior vena cava constriction (15), it has been shown that aldosterone hypersecretion may occur without or preceding any change of arterial plasma electrolyte concentration.

Davis and associates (16) and Ganong and Mulrow (17) have reported that dogs with hypophysectomy and nephrectomy showed no aldosterone response to hemorrhage, and Davis, Ayers, and Carpenter (18) report nephrectomy caused an $80 \%$ reduction of aldosterone and corticosterone response to caval constriction and sodium depletion in hypophysectomized dogs.

There are a number of conflicting reports concerning the influence of ablations of the pineal and of parts of the central nervous system on aldosterone $(15,19-25)$. The measurement of corticosteroid secretion of sodium-depleted animals in which a midcollicular decerebration was associated with removal of the hypophysis, pineal, and subcommissural organ and both kidneys apparently would answer the question whether these structures are essential for the increased aldosterone secretion.

\section{Methods}

Twenty-seven crossbred Merino wethers (25 to $45 \mathrm{~kg}$ ) were used. The experiments were arranged in three main groups, the division depending upon the state of sodium balance and the order of the surgical procedures. Eight animals were sodium replete and the other 19 were depleted of 300 to $500 \mathrm{mEq}$ of sodium. Nine of the depleted sheep came to the final experiment with both kidneys, and ten had been subjected to right nephrectomy six to 68 days before the experiment.

\section{Preliminary preparation of animals}

In each sheep a right unilateral parotid fistula and right carotid loop (26) were made 2 to 10 weeks previ- 
TABLE I

Effect on aldosterone secretion in adrenal vein plasma, micrograms per hour of the sequence of ablations listed. Group NDN (nephrectomy, decerebration, nephrectomy)*

\begin{tabular}{|c|c|c|c|c|c|c|c|}
\hline \multirow[b]{2}{*}{ Sheep } & \multirow{2}{*}{$\begin{array}{c}\begin{array}{c}\text { Left nephrec- } \\
\text { tomy as } \\
\text { zero time }\end{array} \\
\begin{array}{c}0.5-2 \text { hours } \\
\text { later }\end{array}\end{array}$} & \multirow{2}{*}{\multicolumn{3}{|c|}{$\begin{array}{c}\begin{array}{c}\text { Midcollicular decerebration with } \\
\text { pinealectomy and hypophy- } \\
\text { sectomy as zero time }\end{array} \\
\text { Hours later } \\
\end{array}$}} & \multicolumn{3}{|c|}{$\frac{\text { Right nephrectomy as zero time }}{\text { Hours later }}$} \\
\hline & & & & 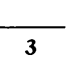 & 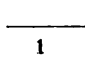 & urs la & 3 \\
\hline $\begin{array}{l}\text { Croesus } \\
\text { Roland } \\
\text { Phineas } \\
\text { Ambrose } \\
\text { Merlin } \\
\text { Horace } \\
\text { Archibald }\end{array}$ & $\begin{array}{r}7.4,5.4 \\
9.8 \\
6.3 \\
14.8 \\
8.8 \\
6.0 \\
11.1\end{array}$ & $\begin{array}{l}5.1 \\
3.3 \\
7.0\end{array}$ & $\begin{array}{r}5.7 \\
0.8 \\
6.1 \\
11.4 \\
9.0 \\
\\
2.0\end{array}$ & 7.5 & $\begin{array}{r}6.4 \\
5.7 \\
14.0 \\
11.3 \\
3.1\end{array}$ & $\begin{array}{l}2.5 \\
2.9\end{array}$ & $\begin{array}{r}17.7 \\
7.3\end{array}$ \\
\hline $\begin{array}{l}\text { Gottlieb } \\
\text { Damien }\end{array}$ & $\begin{array}{l}6.3 \\
7.8\end{array}$ & $\begin{array}{l}2.4 \\
\text { No }\end{array}$ & physe & $\begin{array}{l}3.2 \\
\text { ized }\end{array}$ & \multicolumn{3}{|c|}{ Not right nephrectomized } \\
\hline
\end{tabular}

* In this and Tables II, IV, V, and VI the term "hours later" indicates the time after the ablation designated as zero time that the adrenal blood sample was collected.

ously. Such animals require 40 to $60 \mathrm{~g}$ of $\mathrm{NaHCO}_{3}$ per day to replace the continuous loss of sodium via the parotid saliva. By withholding this supplement, a defined degree of sodium depletion can be established (27). The sodium-depleted animals used in this investigation were deprived of this supplement for 1 or 2 days before the final experiment. To make possible the collection of the total adrenal venous effluent, right adrenalectomy was carried out 6 to 40 days before the experiment. In one group of animals the right kidney was removed at the same operation.

\section{Final experimental procedure}

Throughout each experiment rectal temperature, pulse rate, systolic blood pressure, and respiratory rate were recorded. Systemic systolic blood pressure was measured from a mercury manometer attached to a pneumatic cuff applied to a carotid artery loop, and the end point was determined by palpation.

1) Surgical preparation. The whole procedure was carried out with full asepsis in an operating theater. Induction of anesthesia with 0.3 to $0.7 \mathrm{~g}$ thiopentone iv was followed by intubation and closed circuit anesthesia with oxygen and cyclopropane. The left parotid duct was cannulated for salivary collections. The left carotid artery was separated from the vagus and isolated in case temporary constriction was required for control of hemorrhage during decerebration.

The left kidney was removed through a loin incision, and the renal vein was cannulated with a 4-mm bore polythene tubing filled with heparinized saline. A polythene choker was placed in position around the renal vein at its junction with the inferior vena cava. With this arrangement the outflow from the left adrenal vein was collected episodically.

Midcollicular decerebration was performed after removal of the vault of the skull. In the few instances where the initial cut left the pineal gland or the sub- commissural organ intact, this was widely excised as a wedge of tissue immediately afterwards. After removal of the brain from the cranial cavity, when necessary, hemorrhage was controlled temporarily by constriction of both common carotid arteries in the neck, and permanent hemostasis was achieved by application of gelatin foam to the circle of Willis. At this point anesthesia was discontinued. Hypophysectomy was performed under direct vision after incising the diaphragma sellae. Decerebration and hypophysectomy were completed within a period of 30 minutes. The blood loss did not exceed $150 \mathrm{ml}$ and was usually 30 to $60 \mathrm{ml}$ only. With the majority of animals spontaneous respiration continued throughout the intracranial procedure. In the remainder spontaneous respiration resumed after a short initial period of closed circuit artificial respiration with oxygen. The term decerebration will be used hereafter to cover this series of ablations.

In the series in which the animal had not been right nephrectomized before experiment, that kidney was removed 3 to 4 hours after decerebration.

At the end of each experiment the pituitary fossa was examined macroscopically. In all but two of the sodiumdepleted animals no pituitary tissue remained. In the two instances (Roland and Sophia), fragments of pituitary tissue less than $2 \mathrm{~mm}$ in diameter were found beneath the lip of the pituitary fossa. The fossa of each sodium-replete animal was macroscopically clear.

2) Collection of adrenal venous blood. By tightening the choker around the left renal vein the adrenal venous effluent was diverted from the inferior vena cava, and samples were collected under gravity into graduated cylinders containing heparin. During sampling the cannula was held vertically with the point of outflow 20 to $30 \mathrm{~cm}$ below the level of the inferior vena cava.

3) Parotid saliva. Parotid saliva collections were made from the conscious animal as it stood in the metabolism cage from 1 to 2 hours before the final experiment be- 
TABLE II

Effect on aldosterone secretion in adrenal vein plasma, micrograms per hour of the sequence of ablations listed. Group NND (nephrectomy, nephrectomy, decerebration)

\begin{tabular}{|c|c|c|c|c|c|c|c|c|c|c|}
\hline \multirow[b]{3}{*}{ Sheep } & \multicolumn{5}{|c|}{$\begin{array}{l}\text { Right nephrectomy, } 7-42 \text { days previously } \\
\text { Left nephrectomy as zero time }\end{array}$} & \multicolumn{5}{|c|}{$\begin{array}{l}\text { Midcollicular decerebration with pinealectomy } \\
\text { and hypophysectomy as zero time }\end{array}$} \\
\hline & \multicolumn{5}{|c|}{ Hours later } & \multicolumn{5}{|c|}{ Hours later } \\
\hline & 0.5 & 1 & 2 & 3 & 4 & 1 & 2 & 3 & 4 & 7 \\
\hline Eugene & 15.4 & \multirow{6}{*}{\multicolumn{2}{|c|}{$\begin{array}{r}9.7 \\
14.5\end{array}$}} & \multirow[t]{6}{*}{12.5} & \multirow{7}{*}{15.2} & 7.2 & 8.2 & & 6.7 & \multirow[t]{6}{*}{4.2} \\
\hline Edmund & 11.4 & & & & & & 3.6 & 1.5 & 1.4 & \\
\hline Bolivar & 6.4 & & & & & 2.5 & & 3.6 & & \\
\hline Sophia & 6.7 & & & & & 3.9 & 1.7 & 3.9 & \multirow{3}{*}{3.5} & \\
\hline Horst & & & & & & 6.8 & & & & \\
\hline Gaylord & 7.0 & & & & & & 2.7 & & & \\
\hline Eros & \multicolumn{4}{|c|}{11.9} & & \multicolumn{5}{|c|}{ Not hypophysectomized } \\
\hline
\end{tabular}

gan. The low salivary $\mathrm{Na} / \mathrm{K}$ ratio confirmed a hypersecretion of aldosterone in response to sodium deficiency (1). Collections of saliva were made at approximately half-hourly intervals from the cannulated left parotid duct throughout the experiment.

4) Termination of the experiment. The observation in these experiments continued over 7 to 10 hours. For simplicity of interpretation of results, no pharmacological support of the circulation, or fluid or blood replacement was given. The experiment was terminated at a point where decline of systemic blood pressure and elevation of cardiac rate, or large fall of adrenal blood flow, indicated that the physiological validity of the preparation would be questionable. No results were included in the statistical analyses where blood pressure was below $60 \mathrm{~mm} \mathrm{Hg}$.

\section{Chemical procedures}

Aldosterone, cortisol, and corticosterone were analyzed in adrenal venous plasma by the double isotope dilution derivative procedure $(2,6,28)$. Rates of corticosteroid secretion for each sample of adrenal vein plasma were calculated on the basis of adrenal blood flow and hematocrit.

Sodium and potassium concentrations in plasma and parotid saliva were estimated using a Beckman DU flame spectrophotometer.

TABLE III

Aldosterone secretion rates (mean $\pm S D$ ), micrograms per hour, calculated on mean output for each animal in the period after each ablation*

\begin{tabular}{crcc}
\hline & \multicolumn{2}{c}{$\begin{array}{c}\text { Midcollicular } \\
\text { decerebration } \\
\text { with pineal- } \\
\text { ectomy and } \\
\text { Lroup }\end{array}$} & $\begin{array}{c}\text { Right } \\
\text { nephrectomy }\end{array}$ \\
\hline NDN & $8.6 \pm 2.9$ & $5.7 \pm 3.4$ & $6.5 \pm 4.7$ \\
NND & $10.6 \pm 3.9$ & $3.8 \pm 1.7$ & \\
\hline
\end{tabular}

* Adrenal transplant, $\mathrm{Na}$ replete, $0.63 \pm 0.31$; adrenal transplants' equivalent $\mathrm{Na}$ deficit, $6.85 \pm 2.05 ; \mathrm{NND}$ final output, $3.2 \pm 1.0 ; \mathrm{Na}$-replete NDN controls, $0.7 \pm 0.5$.

\section{Results}

These will be described for sodium-replete and sodium-depleted groups. In those where a preliminary right nephrectomy had been done, the order of procedure was $\mathrm{N}$ (nephrectomy), $\mathrm{N}$ (nephrectomy), D(decerebration)-NND. For the others, it was NDN.

\section{Effects of ablations in sodium-replete sheep}

The ablation NDN was carried out on eight sodium-replete animals. The initial corticosteroid secretion rates observed in these eight sodiumreplete, anesthetized, surgically traumatized animals were (mean $\pm \mathrm{SD})$ : aldosterone, $2.2 \pm 0.8$ $\mu \mathrm{g}$ per hour, corticosterone, $182 \pm 97 \mu \mathrm{g}$ per hour, and cortisol, $1,376 \pm 659 \mu \mathrm{g}$ per hour; $1 \frac{1}{2}$ to 3 hours after completion of decerebration the outputs were: aldosterone, $1.7 \pm 0.9 \mu \mathrm{g}$ per hour, corticosterone, $42 \pm 21 \mu \mathrm{g}$ per hour, and cortisol, $298 \pm 275 \mu \mathrm{g}$ per hour. The mean rates determined 3 hours after the second nephrectomy were: aldosterone, $0.7 \pm 0.5 \mu \mathrm{g}$ per hour, corticosterone, $12 \pm 6 \mu \mathrm{g}$ per hour, and cortisol, $71 \pm 67 \mu \mathrm{g}$ per hour, which are in the lower range observed in the conscious well-trained sodium-replete animal with an adrenal transplant. As three of the eight animals in this series were not right adrenalectomized beforehand, the corticosteroid output of these three animals was multiplied by two in order to approximate the output of the hypertrophied single adrenal. Consideration of aldosterone secretion in relation to the ablations and time elapsed was suggestive, although not conclusive, that removal of the second kidney was associated with a 
CROESUS 22/11/61

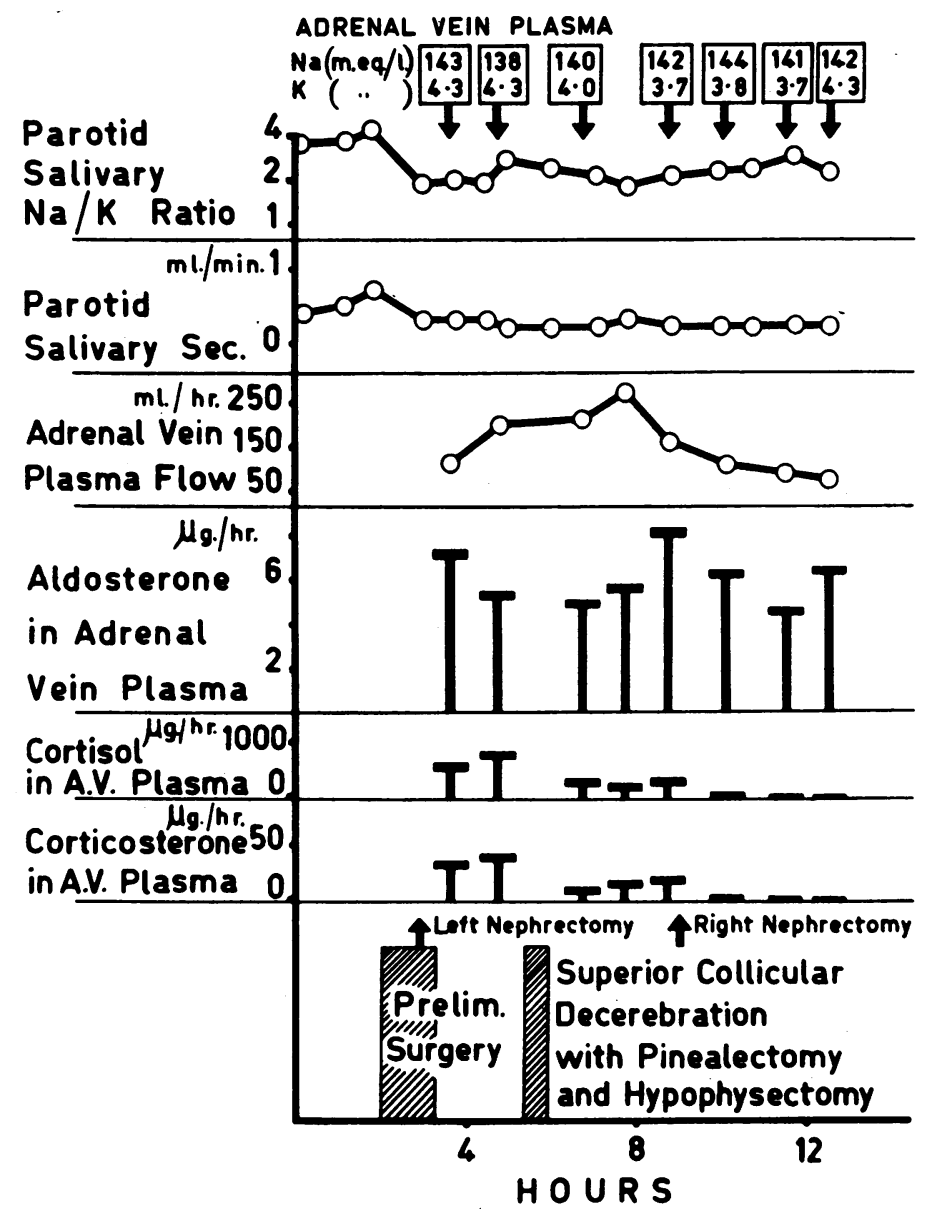

Fig. 1. Croesus (sodium deficient, NDN) : Effect on the ADRENAL SECRETION OF ALDOSTERONE, CORTISOL, AND CORTICOSTERONE OF THE ABLATION PROCEDURES DESIGNATEd IN THE LOWER SECTION, IN THE ORDER SHOWN. The parotid salivary $\mathrm{Na} / \mathrm{K}$ ratio, parotid secretion rate, rate of adrenal venous plasma flow, and the concentrations of sodium and potassium in adrenal venous plasma are shown also.

decline of aldosterone secretion rate further to that caused by decerebration.

\section{Effects of ablations in sodium-deficient sheep}

A. Aldosterone secretion. The results on aldosterone secretion in sodium-depleted sheep are shown in Tables I and II. The mean aldosterone output for each experimental group during the period following each ablation is shown in Table III. The values shown are the averages of the mean output for each animal during the period. The validity of using the mean value for each ani- mal to represent a series of outputs in the period following each ablation step was established by demonstrating the absence of a relationship between time elapsed and aldosterone secretion rate during each period.

The results were examined statistically. Within the group NND and within the group NDN, tests of significance were performed by paired $t$ test. The mean aldosterone output for each animal after each ablation step was used as the control for testing the effect of the subsequent ablation. Comparison between group NDN and NND before 


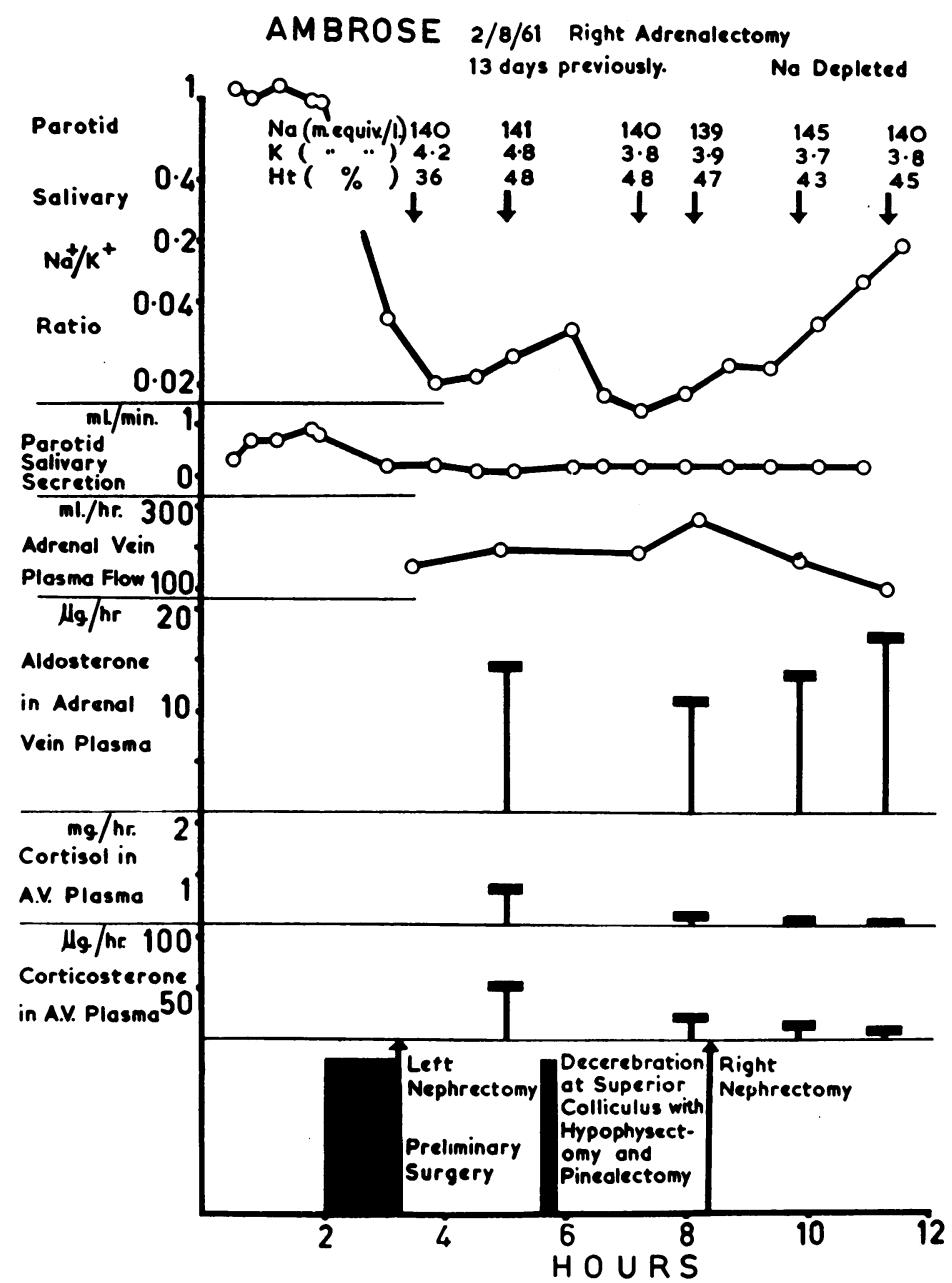

Fig. 2. Ambrose (sodium deficient, NDN) : EfFect on the AdRenal SECRETION OF ALDOSTERONE, CORTISOL, AND CORTICOSTERONE OF THE ABLATION PROCEDURES DESIGNATED IN THE LOWER SECTION, IN THE ORDER SHown. The parotid salivary $\mathrm{Na} / \mathrm{K}$ ratio, parotid secretion rate, rate of adrenal venous plasma flow, and the concentrations of sodium and potassium in adrenal venous plasma are shown also.

decerebration was carried out by $t$ test of group means.

The following features of these results should be noted:1) When the pituitary and central nervous system was intact, total nephrectomy did not cause a reduction in the output of aldosterone. There is no evidence of a fall in aldosterone secretion rate during the predecerebration period of group NND. There is no significant difference between the mean aldosterone outputs of the NDN and NND series before the decerebration step $(0.25>p>0.10)$. The animals of both series were subjected to similar surgery and blood loss.

2) Decerebration with hypophysectomy and pinealectomy had a barely significant effect on the aldosterone output of the NDN series $(p<0.05)$. With the NND series there was a highly significant reduction ( $p<0.01$ ), of early onset, not increasing regularly with time, and at the finish the secretion rates were two to six times the final rates for the sodium-replete animals.

3) The second nephrectomy in the NDN series did not affect aldosterone output significantly 


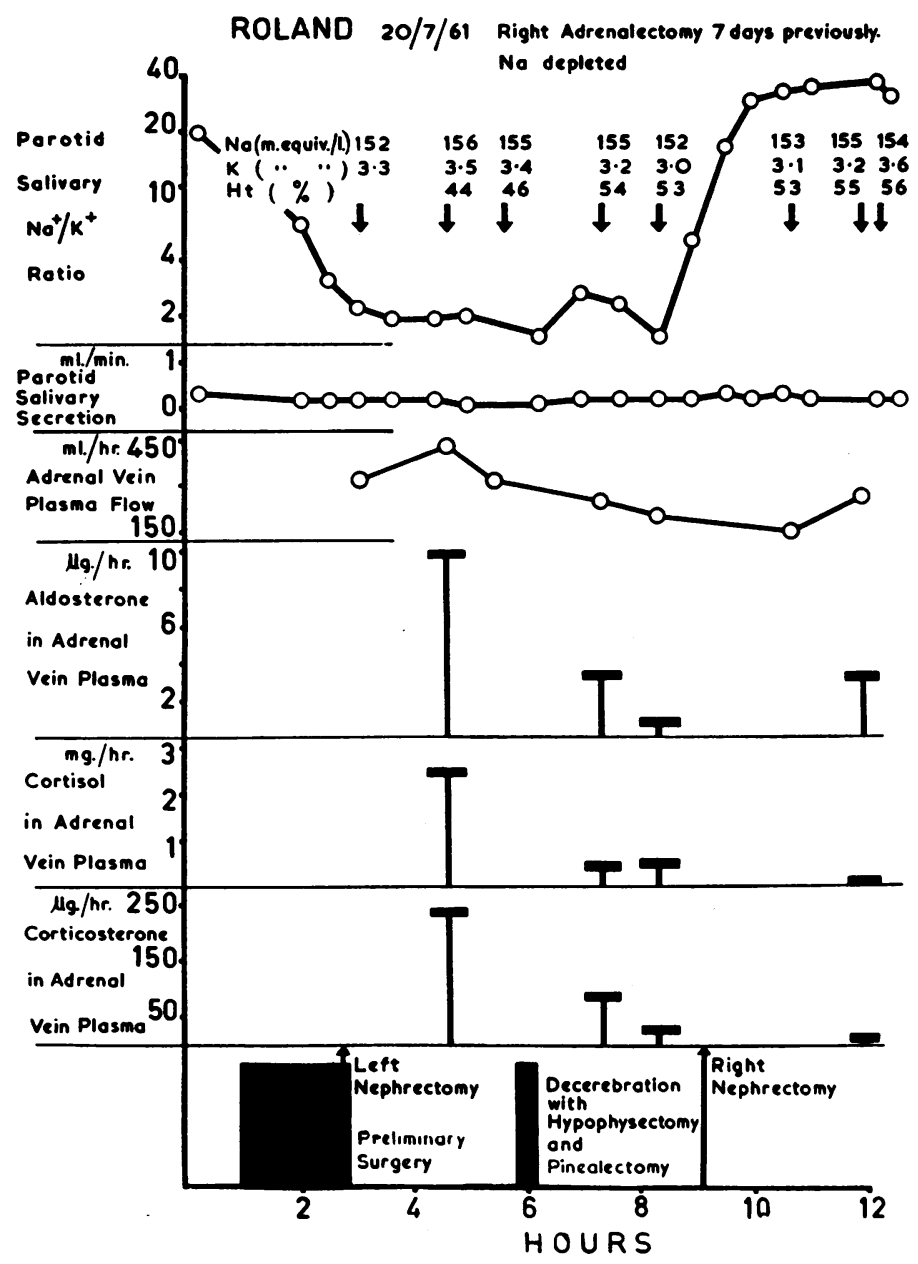

Fig. 3. Roland (SODIUM Deficient, NDN) : EFFect on the ADRENAL SECRETION OF ALDOSTERONE, CORTISOL, AND CORTICOSTERONE OF THE ABLATION PROCEDURES DESIGNATED IN THE LOWER SECTION, IN THE ORDER SHOWN. The parotid salivary $\mathrm{Na} / \mathrm{K}$ ratio, parotid secretion rate, rate of adrenal venous plasma flow, and the concentrations of sodium and potassium in adrenal venous plasma are shown also.

$(0.80>p>0.70)$, and there was no evidence of fall with time after this nephrectomy. The final rates of aldosterone secretion 1 to 3 hours after the completion of all ablations were four to 25 times the final rates observed in the sodium-replete control ablation series.

The correlations in time between the ablations, the corticosteroid secretion rates, the adrenal blood flow, the parotid salivary $\mathrm{Na} / \mathrm{K}$ ratio, and the sodium and potassium concentration in the plasma are shown for some individual experiments in Figures 1 to 6 .
B. Glucocorticoid secretion. The changes in glucocorticoid secretion are shown in Table IV. There was no difference between the predecerebration levels in the sodium-replete and the NND and NDN sodium-deficient series for either cortisol or corticosterone.

Decerebration with hypophysectomy was invariably followed by a large fall in the rates of secretion of cortisol and corticosterone in adrenal vein plasma. This reduction was clear-cut 1 to 2 hours after hypophysectomy and involved an 80 to $90 \%$ decline in output in many experiments. 


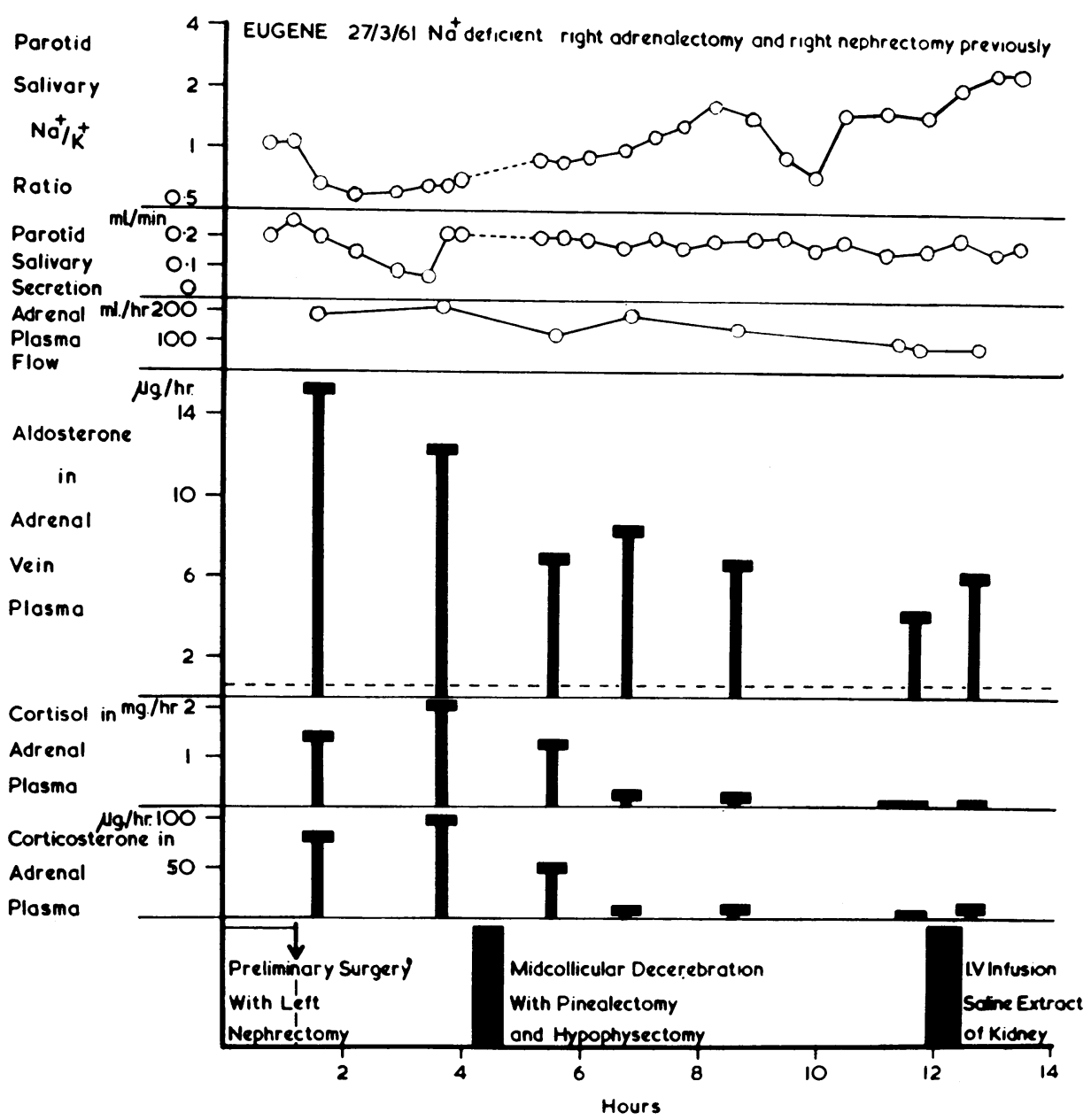

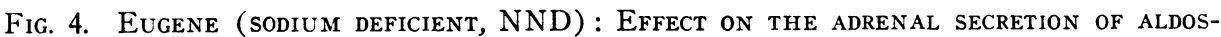
TERONE, CORTISOL, AND CORTICOSTERONE OF THE ABLATION PROCEDURES DESIGNATEd IN THE LOWER SECTION, IN THE ORDER SHOWN. The parotid salivary $\mathrm{Na} / \mathrm{K}$ ratio, parotid secretion rate, and rate of adrenal venous plasma flow are shown also. On the aldosterone scale, the interrupted line represents the mean rate of secretion in conscious sodium-replete sheep. At the 12th hour, the supernatant fluid of a saline homogenate of the animal's kidney was infused intravenously.

In most instances after 3 to 4 hours the outputs of cortisol were within the range observed in conscious undisturbed sheep with adrenal transplants (2). The variability in rates of decrease of cortisol and corticosterone secretion may be attributable to individual variations in the rate of disappearance of circulating ACTH. The instances of slow decline in cortisol and corticosterone outputs were not confined to one group of experiments, although there is some suggestion that decline in output was more precipitate in the group that was bilaterally nephrectomized before hypophysectomy and decerebration ('Table IV,
NND). In the group NDN (Table IV) a small further fall in cortisol and corticosterone secretion followed removal of the second kidney. This was in contrast to the finding with aldosterone, but cannot be attributed with certainty to the nephrectomy rather than passage of time after decerebration. In Damien, subjected to bilateral nephrectomy without decerebration, the cortisol output was only slightly reduced 3 hours after the second nephrectomy.

C. Adrenal blood flow rate and systemic blood pressure. The rates of adrenal blood flow and the systemic systolic blood pressure recorded at 


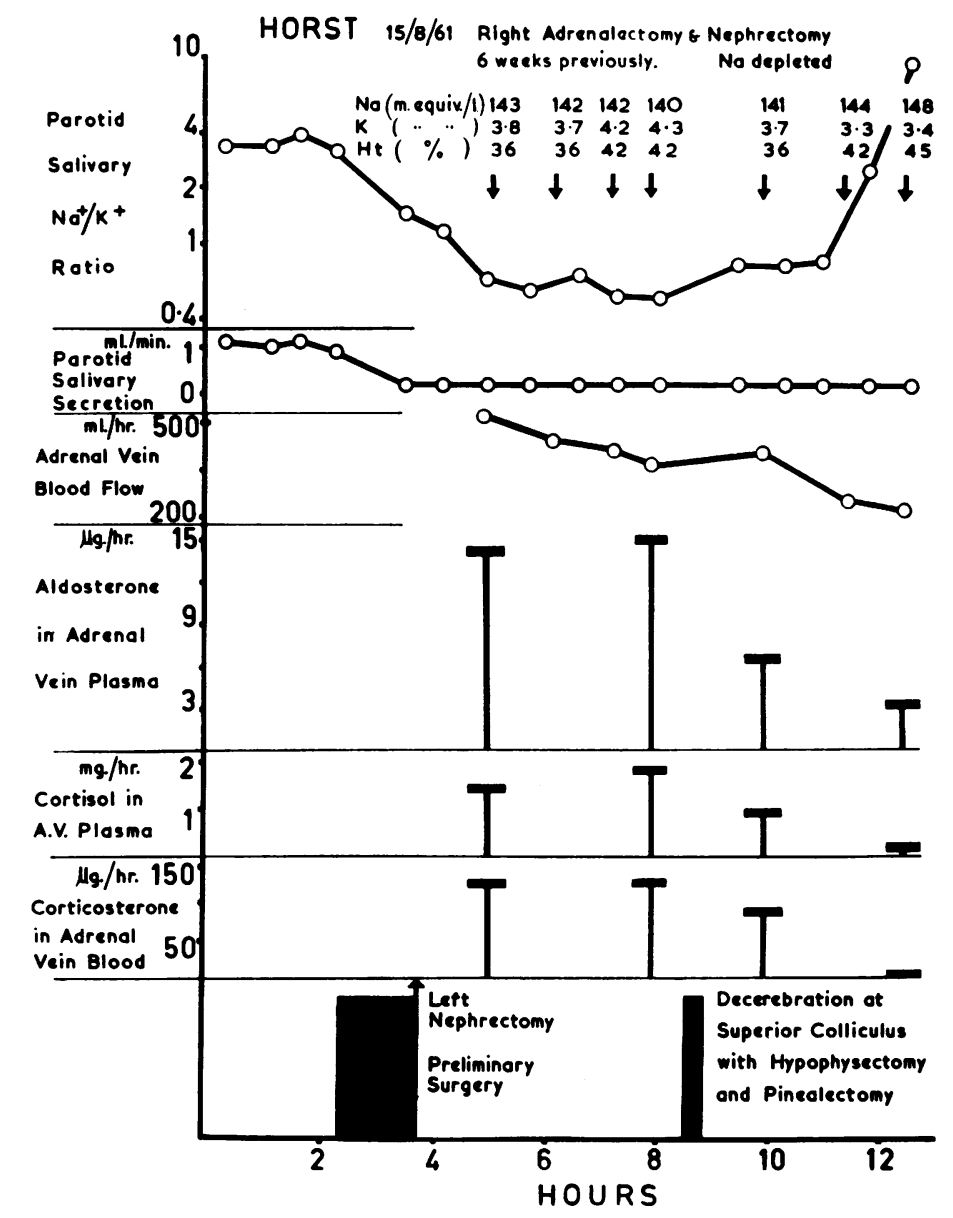

Fig. 5. Horst (SODIUM Deficient, NND): EFfect on the ADRENAL SECRETION OF ALDOSTERONE, CORTISOL, AND CORTICOSTERONE OF THE ABLATION PROCEDURES DESIGNATED IN THE LOWER SECTION, IN THE ORDER SHOWN. The parotid salivary $\mathrm{Na} / \mathrm{K}$ ratio, parotid secretion rate, rate of adrenal venous plasma flow, and the concentrations of sodium and potassium in adrenal venous plasma are shown also.

the time of each adrenal venous collection are shown in Table V. The rate of adrenal blood flow did not differ significantly between the two groups NDN and NND $(9.06 \pm 3.86$ and $9.09 \pm 3.83$, respectively) before the intracranial ablation. After the decerebration the adrenal blood flow and blood pressure declined in most, but not all, instances. The change involved as much as a $50 \%$ reduction in blood flow in some experiments, but, as indicated in others, little or no change occurred. In the group NDN the removal of the second kidney was followed by a decline of blood pressure and blood flow. No results have been included in the statistical analysis where systolic blood pressure was less than $60 \mathrm{~mm} \mathrm{Hg}$.
D. Plasma sodium and potassium concentrations. The concentrations of sodium and potassium were measured in the specimens of adrenal venous plasma and are recorded in Figures 1 to 6 and summarized in Table VI. Considering the whole experimental series, the changes observed were small, and the main trend was a rise of plasma sodium concentration, and a small fall, or no change, of plasma potassium concentration. As shown in Figures 1 to 6 , in some instances the plasma electrolyte composition was the same at the end of the experiment as at the beginning. The mean concentration of potassium in 25 specimens of blood from conscious sodium-replete animals was $4.4 \pm 0.4 \mathrm{mEq}$ per $\mathrm{L}($ meal $\pm \mathrm{SD})$, 


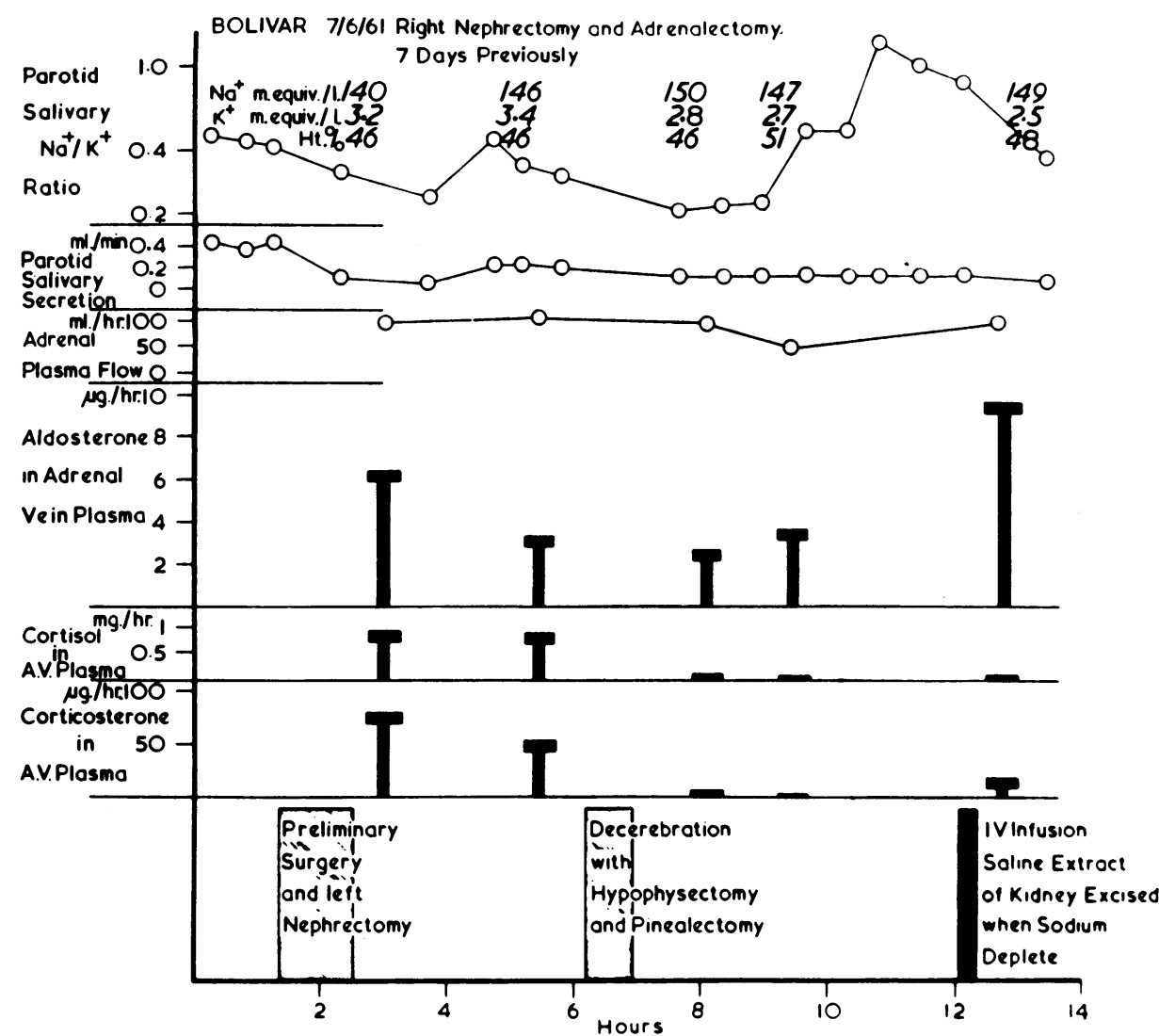

Fig. 6. Bolivar (Sodium deficient, NND) : EfFect on the adrenal secretion of aldosTERONE, CORTISOL, AND CORTICOSTERONE OF THE ABLATION PROCEDURES DESIGNATED IN THE LOWER SECTION, IN THE ORDER SHOWN. The parotid salivary $\mathrm{Na} / \mathrm{K}$ ratio, parotid secretion rate, and rate of adrenal venous plasma flow are shown also. At the 12th hour, the supernatant fluid of a saline homogenate of the animal's kidney was infused intravenously, with resultant rise of aldosterone secretion rate.

and the sodium concentration was $147+3.7 \mathrm{mEq}$ per $\mathrm{L}$ (mean $\pm \mathrm{SD})$. Figure 7 shows the trend of plasma potassium concentration over the course of the NDN experiments in relation to aldosterone secretion. It was observed that the hematocrit rose 5 to $10 \%$ after the intracranial ablation in most of the experiments.

E. Temperature and respiration rate. In all experiments of the series, the rectal temperature remained in the range of 36.5 to $39^{\circ} \mathrm{C}$ during the experiment. Respiration rate was in the range of 12 to 30 per minute.

$F$. The parotid salivary $\mathrm{Na} / \mathrm{K}$ ratio. The normal salivary $\mathrm{Na} / \mathrm{K}$ ratio of sheep's parotid saliva is about $170 / 5=34$. In severe sodium depletion the ratio may be as low as $10 / 170=0.06$. The salivary $\mathrm{Na} / \mathrm{K}$ ratio of the collections made on the conscious animal in the metabolism cage was generally considerably higher than that recorded at the end of the preparative surgery (Figures 1, 2,3 , and 5). This was partly attributable to the operation causing decreased salivary secretion rate, which of itself reduces salivary $\mathrm{Na} / \mathrm{K}$ ratio (1), and also to increased secretion of aldosterone induced by surgical trauma. In these experiments there was a close correlation between the salivary $\mathrm{Na} / \mathrm{K}$ ratio reflecting peripheral aldosterone level and the adrenal aldosterone secretion rate as measured directly by the double isotope dilution method. This is provided due allowance is made for the time delay of 90 to 120 minutes for effect on the parotid, a delay attributed to the half-life of aldosterone and the 60- to 90-minute delay time of the direct response of the parotid to 
TABLE IV

Effect on cortisol and corticosterone secretion in adrenal vein plasma, micrograms per hour of the sequence of ablations listed*

A. Group NDN (nephrectomy, decerebration, nephrectomy)

\begin{tabular}{|c|c|c|c|c|c|c|c|}
\hline \multirow[b]{3}{*}{ Sheep } & \multirow{3}{*}{$\begin{array}{l}\text { Left nephrectomy } \\
\text { as zero time } \\
0.5-2 \text { hours later }\end{array}$} & \multirow{2}{*}{\multicolumn{3}{|c|}{$\begin{array}{c}\begin{array}{c}\text { Midcollicular decerebration with } \\
\text { pinealectomy and hypophysectomy } \\
\text { as zero time }\end{array} \\
\text { Hours later }\end{array}$}} & \multirow{2}{*}{\multicolumn{3}{|c|}{$\frac{\text { Right nephrectomy as zero time }}{\text { Hours later }}$}} \\
\hline & & & & & & & \\
\hline & & 1 & 2 & 3 & 1 & 2 & 3 \\
\hline \multirow{7}{*}{$\begin{array}{l}\text { Croesus } \\
\text { Roland } \\
\text { Phineas } \\
\text { Ambrose } \\
\text { Merlin } \\
\text { Horace } \\
\text { Archibald }\end{array}$} & \multirow{7}{*}{$\begin{array}{c}580,780(35,41) \\
2,500(240) \\
640(46) \\
800(54) \\
1,820(142) \\
1,480(145) \\
1,900(120)\end{array}$} & 330 (11) & 290 (15) & \multirow[t]{5}{*}{330 (19) } & $75(4)$ & \multirow[t]{5}{*}{$41(1)$} & \multirow{2}{*}{$\begin{array}{l}23(1) \\
80(17)\end{array}$} \\
\hline & & $490(89)$ & $520(31)$ & & & & \\
\hline & & $679(69)$ & $480(40)$ & & 310 (23) & & \multirow{3}{*}{$\begin{array}{l}130(11) \\
230(29)\end{array}$} \\
\hline & & & $310(26)$ & & $200(16)$ & & \\
\hline & & \multirow{3}{*}{$220(21)$} & $330(41)$ & & $590(76)$ & & \\
\hline & & & & \multirow[t]{2}{*}{$260(42)$} & & $40(5)$ & \\
\hline & & & $65(4)$ & & $120(6)$ & $40(1)$ & $8(1)$ \\
\hline $\begin{array}{l}\text { Gottlieb } \\
\text { Damien }\end{array}$ & $\begin{array}{l}1,510(108) \\
1,130\end{array}$ & \multicolumn{3}{|c|}{$\begin{array}{l}310(40) \\
\text { Not hypophysectomized }\end{array}$} & \multicolumn{3}{|c|}{$\begin{array}{c}\text { Not right nephrectomized } \\
930\end{array}$} \\
\hline
\end{tabular}

B. Group NND (nephrectomy, nephrectomy, decerebration)

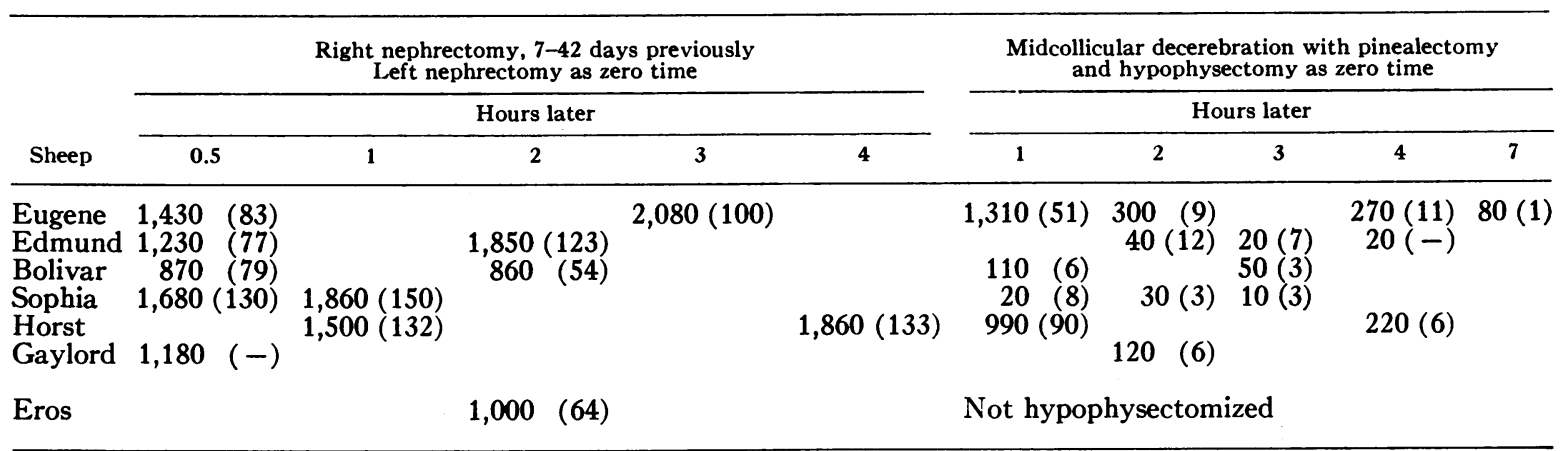

* Corticosterone values are in parentheses.

change of peripheral blood aldosterone concentration $(20,29)$. Figures 1 to 6 , in which salivary $\mathrm{Na} / \mathrm{K}$ ratio is graphed on a logarithmic coordinate, show, this relation. With Croesus (Figure 1) and Ambrose (Figure 2), aldosterone remained high after all ablations, and correspondingly salivary $\mathrm{Na} / \mathrm{K}$ ratio remained low throughout. With Ambrose the ratio was very low (0.02) and near the asymptote of the dose response curve relating aldosterone infusion rate to parotid salivary $\mathrm{Na} / \mathrm{K}$ ratio (29). The fall of aldosterone secretion rate observed 2 hours after decerebration was followed 2 hours later by a rise of $\mathrm{Na} / \mathrm{K}$ ratio. Salivary collections were not continued long enough to reflect the later rise of aldosterone secretion rate. Roland (Figure 3 ) differed from others in the series in that he was depleted of a small amount of sodium only (salivary $\mathrm{Na} / \mathrm{K}=20$, Figure 3; plasma sodium $=156 \mathrm{mEq}$ per $\mathrm{L}$, Table VI). The preliminary surgery caused a large initial fall of salivary $\mathrm{Na} / \mathrm{K}$ ratio unrelated to salivary secretion rate change. The intracranial ablation caused a precipitate decline of aldosterone secretion to $0.8 \mu \mathrm{g}$ per hour and salivary $\mathrm{Na} / \mathrm{K}$ ratio rose towards normal 120 minutes after the ablation. With Eugene (Figure 4) the aldosterone secretion rate decreased over the course of the experiment and salivary $\mathrm{Na} / \mathrm{K}$ rose from 0.7 to 2.5 , a change representing a $60 \%$ decline of potassium concentration. With Horst (Figure 5), 2 hours after the intracranial ablation the salivary $\mathrm{Na} / \mathrm{K}$ ratio rose to 10 associated with an $80 \%$ decrease of aldosterone secretion. In some of the sodium-replete animals there was a small fall of salivary $\mathrm{Na} / \mathrm{K}$ after preliminary surgery, consistent with stimulation of aldosterone secretion 
TABLE V

Effect of the adrenal blood flow (milliliters per minute) and mean systolic blood pressure (millimeters $\mathrm{Hg}$ )*

A. Group NDN (nephrectomy, decerebration, nephrectomy)

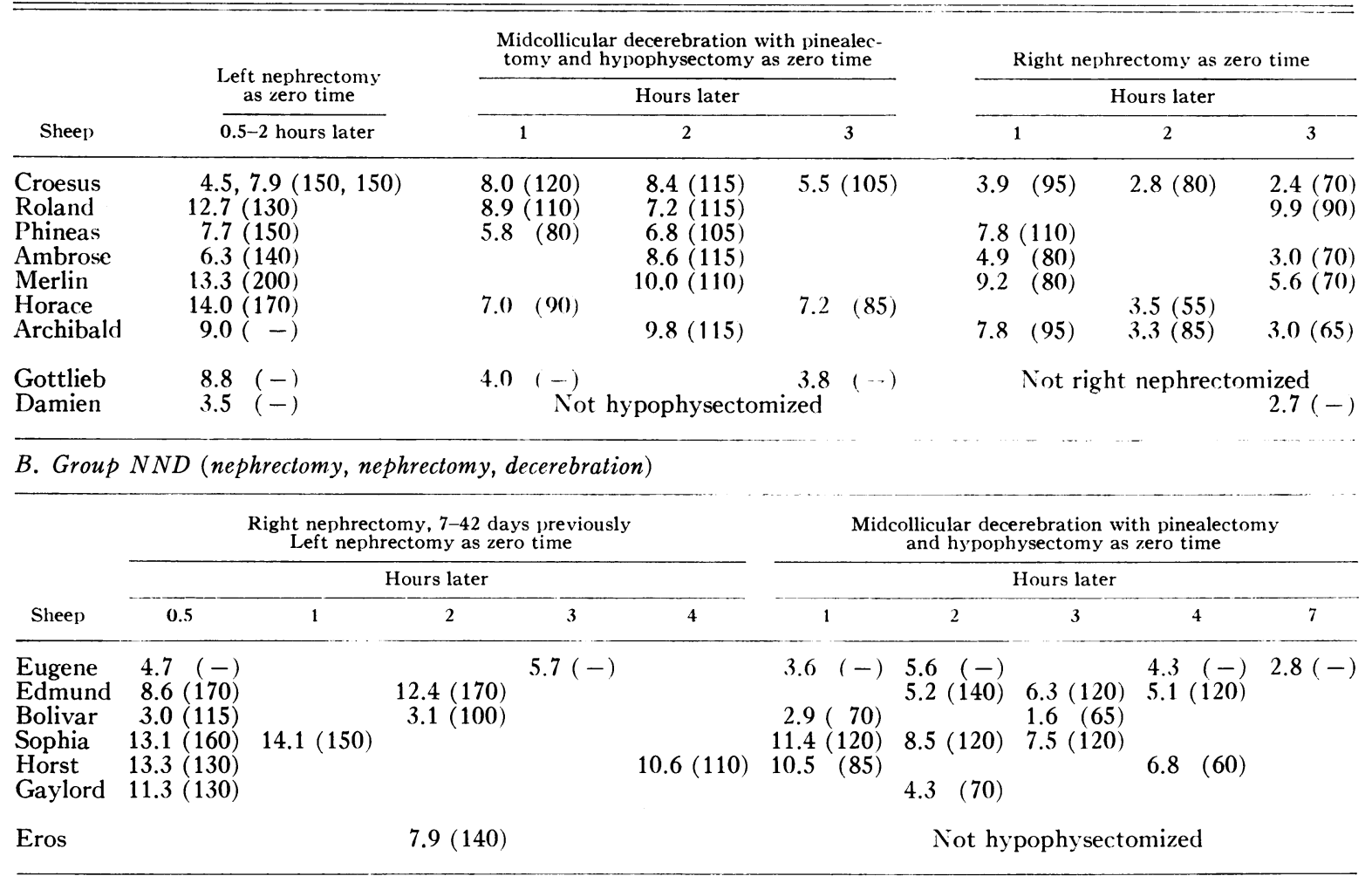

* Blood pressure readings in parentheses.

above parotid threshold. After the ablations aldosterone secretion decreased, and salivary $\mathrm{Na} / \mathrm{K}$ rose to normal.

G. Verification of specificity of aldosterone assay. In addition to the experiments reported above, two experiments were made for the particular purpose of a comprehensive check on the specificity of the aldosterone assay and also to determine whether any large increase in peripheral blood concentration of aldosterone occurred during the experiment. The sequence of surgical procedures was nephrectomy, decerebration, nephrectomy (NDN), and the results in relation to effect on aldosterone secretion are shown in Table VII. The plan of the experiment was that adrenal venous blood was collected before decerebration, 3 hours after decerebration after which the second kidney was removed, and then again 3 hours after nephrectomy. Corresponding specimens of carotid arterial blood were collected before the second kidney was removed and 3 hours afterwards. Thus fewer adrenal venous specimens of double the usual volume were collected, and additional $\mathrm{C}^{14}$ aldosterone was added to them so that the specimens could be divided into samples at the appropriate stage of the analytical procedure. The main points to which attention is drawn in Table VII are: 1) As well as the routine procedure (A), which in our laboratory always involves the oxidation step before the third chromatography, three to seven other procedures ( $B$ to $H$ ) were carried out to verify the radiochemical purity. The specimen of adrenal venous plasma (11 to 43 $\mathrm{ml}$ ) was processed to the stage of second chromatography and then divided into samples for the purpose of formation of other derivatives. These procedures are listed in the key to Table VII, and it is shown clearly that they did not result in any significant change in the aldosterone content of the sample (i.e., the $\mathrm{H}^{3} / \mathrm{C}^{14}$ ratio) as determined 
TABLE VI

Effect on sodium and potassium concentrations in adrenal vein plasma*

A. Group NDN (nephrectomy, decerebration, nephrectomy)

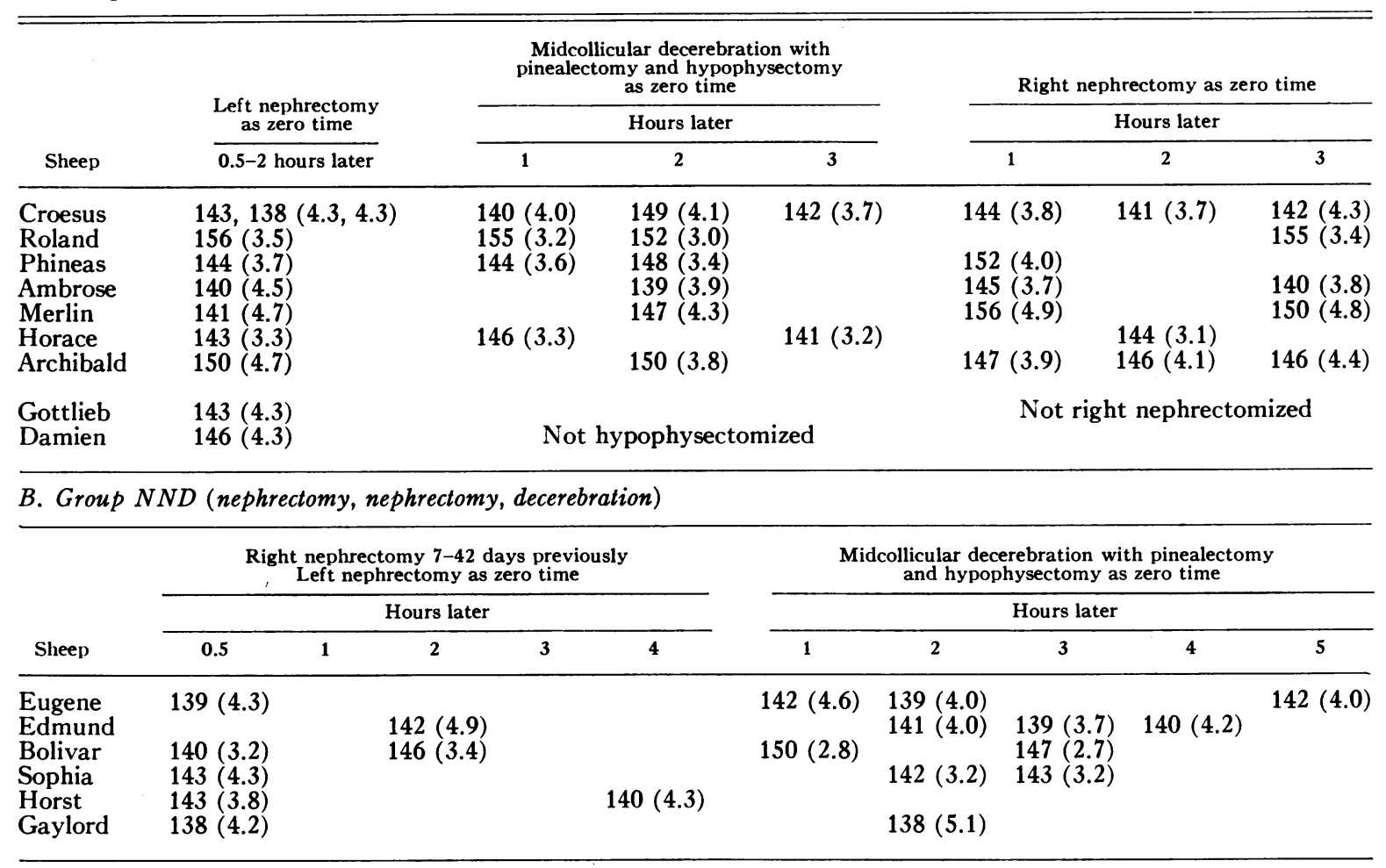

* Potassium concentrations in parentheses.

by the routine method $\mathrm{A}$. These two experiments show a persistent hypersecretion of aldosterone 3 to 4 hours after nephrectomy of a decerebrate animal, similar to the results reported in Table $I$. With Archibald (Table I) the procedures B and $C$ were carried out on all specimens of adrenal venous blood, and procedures $\mathrm{E}$ and $\mathrm{F}$ were carried out as well on the two specimens of blood collected after nephrectomy. In addition, a further procedure not shown in Table VII was followed, involving recovery of all specimens of Archibald treated as $\mathrm{C}$ from phosphor and running a fourth chromatogram after acid hydrolysis. None of these procedures resulted in significant change from the results listed on Table I. Eight specimens from other animals in Tables I and II, including the final specimen after nephrectomy from Ambrose, who had a very high aldosterone output, treated by procedure B showed no significant change.
2) The final specimen of adrenal venous blood drawn from Jacinth was analyzed as whole blood. Consistent with earlier results (6) that aldosterone distributes equally over red cells and plasma in sheep adrenal venous blood and the fact that the packed cell volume had risen to $55 \%$, the aldosterone secretion rate determined from whole blood assay was approximately double that estimated in the immediately previous adrenal venous plasma sample. This specimen was submitted to the series of specificity checks indicated by $\mathrm{C}$ to $\mathrm{H}$ and validates the normal procedure. The result draws attention to the fact that an increase in hematocrit was a consistent finding during the experiments reported in Tables I and II, and therefore, the final aldosterone secretion rates based on analyses of adrenal venous plasma underestimate the persistence of adrenal secretion of aldosterone relative to the initial output. Cortisol and corticosterone secretion rates estimated from whole blood 


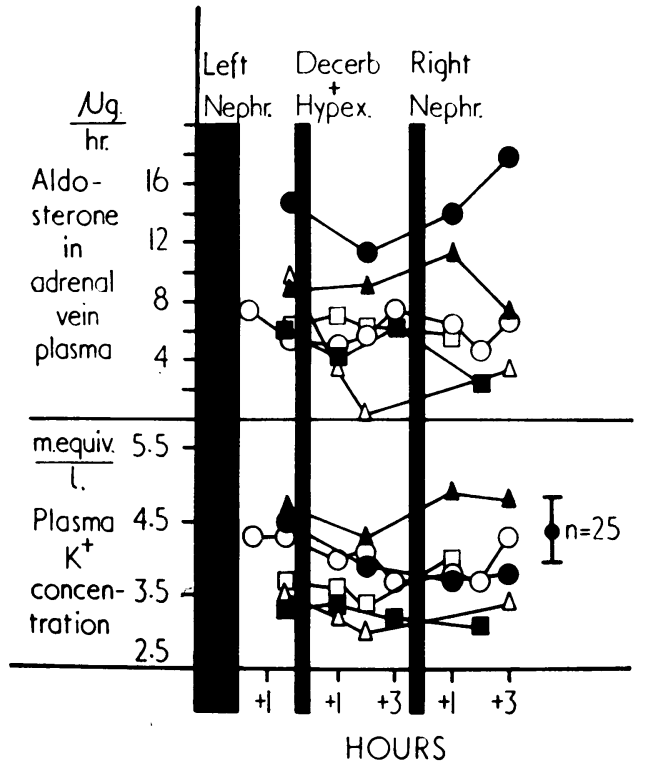

Fig. 7. Group NDN (sodicy deficient): VariaTIONS IN THE SECRETION RATE OF ALDOSTERONE (upper panel) AND PLASMA POTASSILM CONCENTRATION (lower panel) DURING THE course OF EACH EXPERIMENT. The ablations are designated at the top and are displayed as vertical black bars. $\boldsymbol{\Delta}$, Merlin; $\boldsymbol{O}$, Ambrose; $\bigcirc$, Croesus ; $\triangle$, Roland ; $\boldsymbol{\square}$, Horace ; $\square$, Phineas.

were the same as in the previous plasma sample, indicating a continuing fall in secretion rate during the time elapsed between the two bleeds.

3) During these experiments there was a fall of potassium concentration and a small rise of plasma sodium concentration. Stimulation of the adrenal by direct effect of plasma ionic change was not a factor in the aldosterone secretion rates finally observed, which were five to seven times higher than observed in the sodium-replete controls 3 hours after nephrectomy.

4) The analyses of $25 \mathrm{ml}$ of systemic arterial plasma were made formally to eliminate the possibility that a large unaccounted accumulation of aldosterone, or some aldosterone mimic in peripheral plasma, may have contributed a false estimate of adrenal secretion rate in the final specimens, since the true secretion rate represents the difference between adrenal venous and arterial concentration of aldosterone. In both animals before and after nephrectomy, the estimates were indistinguishable from the blank of the method as determined on peripheral plasma of adrenalectomized sheep, $0.04 \mu \mathrm{g}$ per $100 \mathrm{ml}$. With the adrenal plasma flow rates and aldosterone concentrates observed here (see Table VII), it is clear that any contribution from systemic arterial inflow to the final estimate of aldosterone secretion rate was negligible.

\section{Discussion}

These experiments had the limited objective set out at the end of the introduction, and the results clearly show that sodium-depleted sheep 3 hours after midcollicular decerebration with pinealectomy and hypophysectomy and bilateral nephrectomy have an aldosterone secretion rate higher than sodium-replete animals in the same circumstances; the values were: replete NDN, $0.7 \pm 0.5 \mu \mathrm{g}$ per hour, deplete NDN, $6.5 \pm 4.7$ $\mu \mathrm{g}$ per hour, and deplete NND, $3.8 \pm 1.7 \mu \mathrm{g}$ per hour. The replete and deplete groups were subjected to the same anesthetic, operative procedures, and blood removal; the presumption is therefore that the final high output of aldosterone is due to the sodium depletion. This would be made more certain if experiment showed that infusion of $\mathrm{NaCl}$ to replace the sodium deficit caused the aldosterone output to fall to the aldosterone secretion rate in the replete animals. In two animals, Archibald and Roland, there was little sodium deficit, plasma sodium concentrations in Roland (156 $\mathrm{mEq}$ per L) and Archibald (150 $\mathrm{mEq}$ per L) were much higher than for the other animals, and the initial salivary $\mathrm{Na} / \mathrm{K}$ ratios were 20 and 9 , respectively, compared with 0.4 to 4.0 observed in the other animals. In these animals, where sodium deficit was very small and the main cause of aldosterone hypersecretion was trauma, the secretion rate did decline precipitately after decerebration and hypophysectomy, whereas in the severely sodium-deficit animals this did not occur. This suggests that continued hypersecretion of aldosterone in the sodium-deficient animals was not a consequence of trauma but rather due to continued response to sodium deficiency. Previous experiments from this laboratory, however, have shown that aldosterone hypersecretion may continue in the decerebrate sodium-deficient animal, but replacement of sodium by intravenous infusion does not turn it off if the decerebration is at the midcollicular region, or posterior to it $(20,25,30)$. These observations were based on the use of the salivary $\mathrm{Na} / \mathrm{K}$ ratio as an index of 


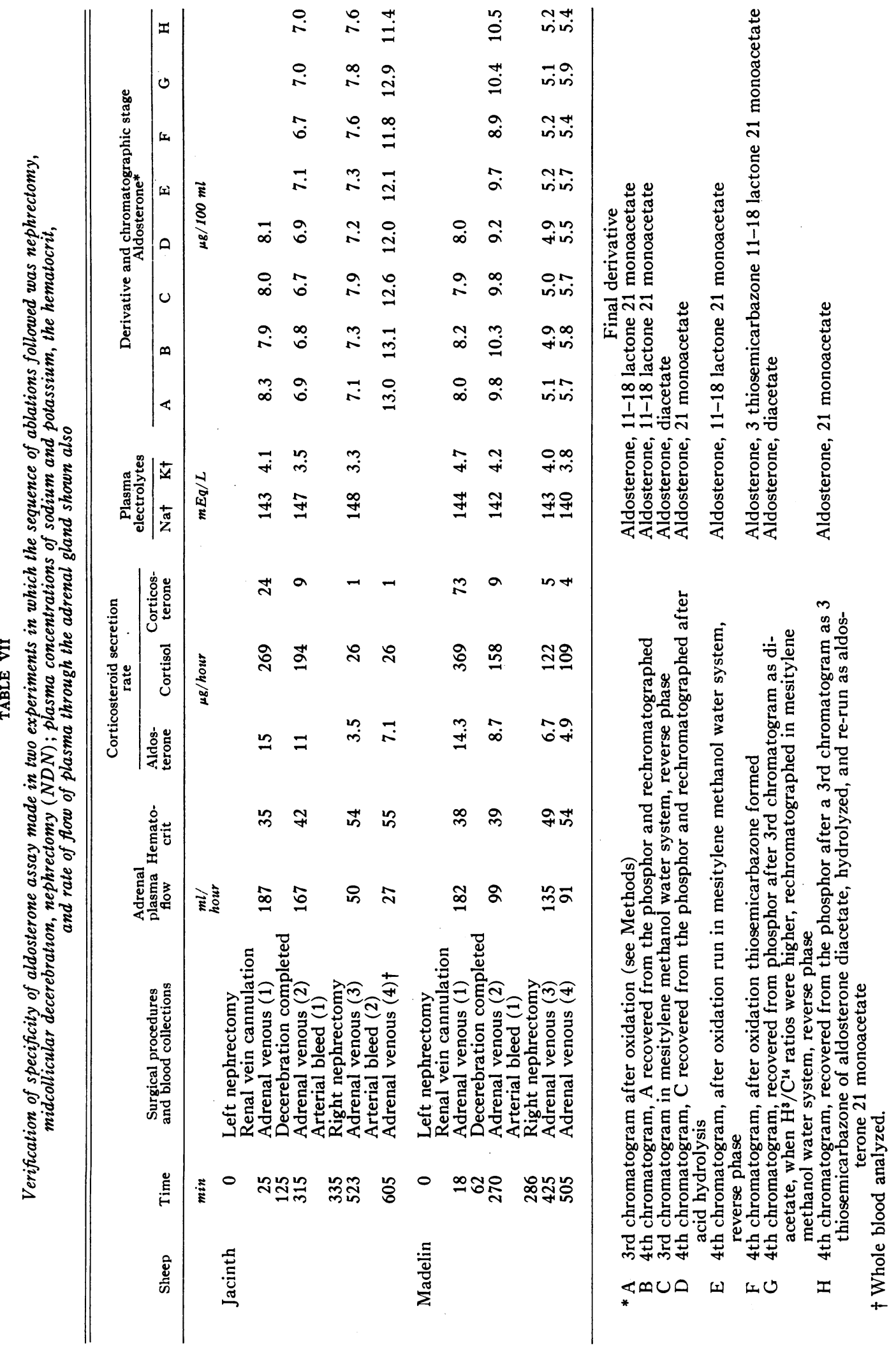


aldosterone secretion. A current investigation in our laboratory involves more comprehensive study of the effect of variable level neural ablation by direct assay of adrenal venous blood. However, unidirectional reactive mechanisms are known to occur in the organization of physiological systems, e.g., with a lesion of the anterior hypothalamus ("heat loss center"), hyperthermia due to the unbalanced activity of the posterior hypothalamus ("heat conservation center") regularly occurs (31-35). Possibly the organization of aldosterone control is complex, and elements influencing the system in opposite directions are separated spatially. A convincing answer to the question of whether hypersecretion of aldosterone which continues after nephrectomy is directly due to the sodium depletion would be provided by reversal by sodium administration in the conscious hypophysectomized arenal animal.

Possible reasons for the continuance of aldosterone hypersecretion in these experiments are: 1) $A C T H$. In sufficiently high doses ACTH stimulates aldosterone secretion directly $(2,6-8)$. In the present study hypophysectomy was done under direct vision; the median eminence, portal vessels, and pituitary stalk were totally removed before incision of the membrana sellae and pituitary removal. In all animals the secretion rates of cortisol and corticosterone subsequently fell to basal levels from the high initial levels associated with anesthesia and surgery. This functional index of hypophysectomy confirms the anatomical evidence. In two animals, Roland and Sophia, where a small pituitary fragment remained adherent to the membrana sellae, the fall of cortisol and corticosterone was to the lowest range observed in the series (Table IV). There was a regular correspondence between the fall of cortisol and corticosterone, but no regular correspondence between the fall of these and aldosterone. In these circumstances it appears certain that the continuance of high aldosterone secretion rates is not due to ACTH support or stimulation. This independence of the secretion rate of aldosterone from that of cortisol and corticosterone seen in the present circumstances is similar to that found in the conscious sodium-depleted sheep with an autotransplanted adrenal gland (2) and conscious dogs with caval constriction (14).
2) Renin-angiotensin. Angiotensin II stimulates aldosterone secretion by direct action on the adrenal $(2,6,36,37)$. In our experience with the sheep there is not a consistent stimulating effect on cortisol or corticosterone secretion $(2,6)$.

In acute experiments adequate time must be allowed for the full effects of a procedure to be disclosed. When sodium deficiency is corrected in a conscious animal by intravenous infusion of the requisite amount of $\mathrm{NaCl}$, the aldosterone secretion rate falls within 40 minutes (38). When a thoracic caval constriction is released in a conscious animal the aldosterone secretion reverses within 20 minutes (39). These observations suggest that ASH (aldosterone-stimulating hormone) is rapidly inactivated in blood under physiological conditions. In relation to the question of the possible postnephrectomy persistence of an aldosterone-stimulating effect attributable to renin and angiotensin, observations usually continued 3 to 4 hours after the second nephrectomy in series NDN, and as long as 7 to 10 hours after the second nephrectomy in the series NND. The biological half-life of angiotensin II in sheep blood is very short, 1 to 2 minutes, as estimated from the pressor effect (6). The half-life of the pressor effect of renin has been estimated at approximately 20 to 30 minutes (40). Cross-circulation experiments of Gross, Regoli, and Schaechtelin (40) have shown disappearance of renin from the circulation by 1 hour in normal anesthetized rats and by 2 hours in anesthetized nephrectomized rats. Carpenter, Davis, and Ayers (10) have shown that blood pressure returns to normal within 15 to 30 minutes of stopping infusion of large amounts of renin in the hypophysectomized nephrectomized dog. A similar observation has been made in the nephrectomized sheep. On available evidence it seems unlikely that renin would persist in the circulation in significant amounts 3 hours after nephrectomy and very unlikely that it would do so for 5 to 7 hours after nephrectomy, unless gradual release from large stores in arterial walls were feasible (41). The possibility must be taken into account also that the duration of after-effect of renin-angiotensin on the adrenal is much greater under these conditions than the duration of pressor effect, although observations of duration of stimulating effect of angiotensin after stopping 
infusion to the adrenal transplant of a conscious sodium-replete animal (6) do not support this possibility. However, the lower final aldosterone secretion rate in the series NND compared with NDN indicates the necessity of considering this question in longer term semisurvival studies. Another formal consideration is that other enzymes released into the circulation by trauma might engender angiotensin I formation from renin substrate, but the sodium-replete controls do not suggest this.

3) Local ionic effects. Increased plasma potassium or decreased plasma sodium, or a combination of these, can give rise to an increasing secretion of aldosterone. In Tables I and VI there is some variation of plasma sodium and potassium in the sheep as the experiments progressed, but there is no regular relation between change in aldosterone secretion and change in plasma sodium or potassium, or both. In none is the ionic variation greater than is expected at the relevant degree of sodium depletion. There was often no change during the experiment, or the trend over the experiment was a rise of sodium and fall of potassium concentration (Figures 1 to 7). In nearly all experiments potassium concentration was in the normal range, and even in Merlin, where it was a little higher than others ( 4.7 to $4.9 \mathrm{mEq}$ per $\mathrm{L}$ ), there was no change of significance over the course of the experiment. Ionic variation per se cannot explain the initial or continuing high aldosterone secretion rate in these experiments.

4) Hemodynamic effects. Bleeding gives rise to increased aldosterone secretion $(15,42)$. In the conscious sheep $240 \mathrm{ml}$ must be removed in 30 minutes to give an increased aldosterone secretion. The removal of 300 to $400 \mathrm{ml}$ as ten to twelve episodes spread over 6 to 10 hours does not increase aldosterone. In the present series total blood loss over many hours was seldom as much as this, although the possibility has to be considered that the sodium-deficient anesthetized animal is more sensitive to this stimulus than the conscious animal. Tables $\mathrm{I}$ and $\mathrm{V}$ show that there is no regular relationship between adrenal blood flow and aldosterone secretion rate and that in general the adrenal blood flow moves in the direction of arterial blood pressure. Similar decline of adrenal blood flow and blood pressure occurred in the sodiumreplete series. The evidence does not suggest that the hemodynamic condition of the sodium-deficient animal can account for the continuance of increased aldosterone secretion rate by some identifiable difference from the sodium-replete series.

The results for the predecerebration period are consistent with those of Davis, Ayers, and Carpenter (18), who found that total nephrectomy did not reduce aldosterone secretion in anesthetized caval-constricted dogs if the hypophysis were intact. They found, however, that nephrectomy of the hypophysectomized sodium-deficient and caval-constricted dogs caused an $80 \%$ reduction of aldosterone and corticosterone secretion, the effect being maximal or nearly maximal within an hour. This, on first sight, is completely at variance with the present observations. There are, however, the following differences between the experiments: $a$ ) The hypophysectomies of Davis and associates (18) were done 2 or 3 days before the final experiment, and no support of the thyroid (thyroid-stimulating hormone, TSH) or adrenal $(\mathrm{ACTH})$ was given in the meantime, although cortisone was administered. Also in this context, Slater (43) has reported that nephrectomy caused a large reduction of aldosterone secretion in the acute hypophysectomized dogs, but if the nephrectomy were done 18 hours later under local anesthesia, there was not a significant decrease of aldosterone. $b$ ) In our series there was also midcollicular decerebration. Evidence published earlier from this laboratory $(20,25)$ and by Davis (15) was contrary to Farrell's findings (44) of a large decline of aldosterone secretion following midcollicular decerebration. When the sodium-deficient animal is anesthetized and subjected to surgery, high plasma ACTH concentration probably contributes to the aldosterone output recorded. In an experiment on Clement (NND), aldosterone had fallen to $55 \%$ of the preliminary observation 100 minutes after completion of all ablations. Intravenous infusion of $500 \mathrm{mU}$ per hour of $\delta_{1}$ ACTH restored aldosterone, and cortisol and corticosterone rates as well, to the preablation level. Double this rate of ACTH infusion increased the secretion of all three corticosteroids above the preablation level. These observations were consistent with the proposition that 
a component of the initial aldosterone secretion was ACTH-stimulated, and moreover suggested that the hypophysectomy was the element of the decerebration procedure which caused the aldosterone decrease. c) After making allowance for the fact that the dogs of Davis and colleagues (18) weighed 15 to $20 \mathrm{~kg}$ against the 25 to 40 $\mathrm{kg}$ of sheep, an important fact is that the degree of sodium deficiency was greater in the sheep study. The maximal loss from the two Mercuhydrin injections in the experiments of Davis and colleagues was $140 \mathrm{mEq}$, whereas the parotid fistulated sheep were depleted of 300 to $500 \mathrm{mEq}$ of sodium. Intracellular ionic changes of moderate to severe sodium deficiency affecting the glomerulosa of the adrenal may sustain the hypersecretion until the intracellular deficit is corrected independently of other humoral stimuli. Some other possibilities have been considered elsewhere (2).

The question of radiochemical purity and the specificity of the aldosterone assay has been carefully considered $(2,6)$. In the double isotope dilution derivative method used here, the $\mathrm{C}^{14}$ aldosterone marker is added to plasma at the outset so that all losses are accounted for. Lack of radiochemical purification could give too high a result. With the double isotope derivative method $(5,8)$ where the marker is added only after extraction and acetylation, there is the additional possibility of unknown handling losses and incomplete esterification, which despite adequate radiochemical purification could lead to a low estimate. Data in relation to the error of the double isotope dilution derivative method and the method blank have been published (2). The constancy of the $\mathrm{H}^{3} / \mathrm{C}^{14}$ ratio across the final chromatogram spot has been checked. The accuracy of the method increases with increasing amount of aldosterone in the sample, e.g., with sodium deficiency. The double isotope method is, however, essentially nonspecific. Serial paper chromatography and derivative formation are used to remove other acetylated steroids, radiochemical impurities arising from the reagents and during the esterification reaction, and other acetylated compounds that could mimic aldosterone. We thought that any hypothetical aldosterone-like contaminant that persisted through development of two chromatograms, the oxidation step, and a third chromatogram might not easily be removed by a single further chromatography in a similar system. To verify the specificity of the routine procedure, the use of other chromatographic systems of a different type and formation of other derivatives were used to give a higher probability that the final $\mathrm{H}^{3} / \mathrm{C}^{14}$ ratio represented aldosterone alone. The results of the specificity experiments carried out along these lines (Table VII) established that radiochemical purification was achieved by the routine assay at this level of aldosterone concentration. There was further evidence which also substantiated this fact in relation to absence of either nonsteroidal radioactive contamination or aldosterone-like steroidal contamination in nephrectomized animals. Thus in each batch of ten to twelve samples analyzed in the experiments here, a pure aldosterone standard or a plasma sample, or both, with a known amount of aldosterone added were run as a control. The blank of the method was checked frequently (2). Also, in many instances specimens from conscious sodium-replete sheep with transplants were included in the same batch with the sodium-deficient nephrectomized animals. The results on the sodiumreplete animals were in the usual basal range, less than $1 \mu \mathrm{g}$ per hour $(2,6)$. Furthermore, the control sodium-replete sheep submitted to the same series of ablations without exception had very low final outputs of aldosterone. In those sodiumdeficient sheep where the ablation caused a significant decrease of aldosterone secretion (e.g., Roland, Horst, and Archibald) the parotid salivary $\mathrm{Na} / \mathrm{K}$ ratio rose, indicating a fall of aldosterone level in peripheral blood, whereas in those animals where the aldosterone remained high, the salivary $\mathrm{Na} / \mathrm{K}$ ratio remained low, i.e., the chemical assay was consistent with this biological index of aldosterone secretion (29). We are satisfied that radiochemical purity was achieved and that in the sodium-deficient animal the large aldosterone secretion assessed after these ablations was valid and not observed in the sodium-replete controls.

The analysis of adrenal venous whole blood, with results consistent with earlier reports on association of aldosterone with red blood cells, emphasized the importance of taking into account the effect of rising hematocrit in any acute experi- 
mental procedure where aldosterone secretion rate is determined by plasma analysis and a fall of secretion rate is recorded. Furthermore, any circumstance which altered the association of aldosterone with red cells over the course of an acute experiment could be an unrecognized cause of either apparent increase or decrease of secretion rate estimated by plasma analyses.

The results now reported mean no more than is permitted by the circumstances in which they were obtained. The main point is that 3 hours after completion of all ablations in both acute series, aldosterone secretion continued at a rate two to 25 times the final rate found in the sodiumreplete controls. In the case of the NND series, this hypersecretion was observed up to 11 hours after the second nephrectomy. We can reasonably conclude that the structures removed by decerebration and nephrectomy are not essential for hypersecretion of aldosterone. Since this set of ablations does not engender similar aldosterone hypersecretion in the sodium-replete animal, we can reasonably conclude that sodium depletion has some causative relation to the hypersecretion of aldosterone in these circumstances, but it is not safe to conclude that it is the sole causative condition. We can probably conclude from the data and arguments set out that the continued hypersecretion of aldosterone is not due, in present circumstances, to the action of $\mathrm{ACTH}$, the reninangiotensin mechanism, or direct electrolyte action on the glomerulosa.

Such conclusions do not, however, answer the question whether in other circumstances with hypersecretion of aldosterone, ACTH, renin-angiotensin, or direct electrolyte actions individually or in combination are in a causative relationship to the hypersecretion of aldosterone. The difficulty of assessing the physiological significance of the results from acute experiments of the present type have been discussed previously $(1,20$, 38 ), and these considerations apply to the present experiments and also to much of the available data on the role of the renin-angiotensin system in aldosterone control. The results emphasize the importance of further experiments in which the influence of nephrectomy is studied over a much longer time in conscious hypophysectomized animals, with the animal supported to prevent endo- crinal atrophy, and in the absence of present or recent trauma or uremic manifestations.

\section{Summary}

The experiments examined the effects of bilateral nephrectomy and midcollicular decerebration with pinealectomy and hypophysectomy on the corticosteroid secretion of sodium-depleted sheep. The sheep were sodium deficient as a result of the loss of 300 to $500 \mathrm{mEq}$ of sodium from a permanent unilateral parotid fistula. A control group of sodium-replete sheep was subjected to the same series of surgical ablations. The experiments in the sodium-deficient state were divided into two groups depending upon whether the condition of bilateral nephrectomy preceded the intracranial ablation by a period of 3 to 4 hours (NND), or followed it after an interval of 3 to 4 hours (NDN). In all instances the observations continued 2 to 7 hours after completion of all ablations. The mean final aldosterone secretion rate of the sodium-replete group was $0.7 \pm 0.5$ (SD) $\mu \mathrm{g}$ per hour, and for the sodium-depleted group the mean final outputs were NDN, $6.5 \pm 4.7$ $\mu \mathrm{g}$ per hour, and NND, $3.8 \pm 1.7 \mu \mathrm{g}$ per hour. This result demonstrated that the hypersecretion of aldosterone evoked by sodium depletion may persist for some hours at two to 25 times the basal rate in the absence of the site of origin of ACTH and the kidneys, the pineal and subcommissural organ, each proposed as a site of origin of aldosterone-stimulating hormone. There was a clear dissociation of aldosterone secretion from cortisol and corticosterone secretion, which fell to basal levels after hypophysectomy. The continued hypersecretion of aldosterone was not attributable to the direct stimulation of the adrenal by changes in the ionic composition of plasma. The studies, which carry the limitations inherent in acute experimentation, suggest that the mechanisms of stimulation of aldosterone secretion are almost certainly complex under these conditions and may not reflect the normal physiological system of control.

\section{References}

1. Denton, D. A., J. R. Goding, and R. D. Wright. Control of adrenal secretion of electrolyte-active steroids. Brit. med. J. 1959, 2, 447 and 522. 
2. Blair-West, J. R., J. P. Coghlan, D. A. Denton, J. R. Goding, M. Wintour, and R. D. Wright. The control of aldosterone secretion. Recent Progr. Hormone Res. 1963, 19, 311.

3. Carpenter, C. C. J., J. O. Davis, J. E. Holman, C. R. Ayers, and R. C. Bahn. Studies on the response of the transplanted kidney and the transplanted adrenal gland to thoracic inferior vena caval constriction. J. clin. Invest. 1961, 40, 196.

4. Fleming, R., and G. Farrell. Aldosterone and hydrocortisone secretion by the denervated adrenal. Endocrinology 1956, 59, 360.

5. Yankopoulos, N. A., J. O. Davis, B. Kliman, and R. E. Peterson. Evidence that a humoral agent stimulates the adrenal cortex to secrete aldosterone in experimental secondary hyperaldosteronism. J. clin. Invest. 1959, 38, 1278.

6. Blair-West, J. R., J. P. Coghlan, D. A. Denton, J. R. Goding, J. A. Munro, R. E. Peterson, and M. Wintour. Humoral stimulation of adrenal cortical secretion. J. clin. Invest. 1962, 41, 1606.

7. Mulrow, P. J., W. F. Ganong, G. Cera, and A. Kuljian. The nature of the aldosterone-stimulating factor in dog kidneys. J. clin. Invest. 1962, 40, 505 .

8. Davis, J. O., N. A. Yankopoulos, F. Lieberman, J. Holman, and R. C. Bahn. The role of the anterior pituitary in the control of aldosterone secretion in experimental secondary hyperaldosteronism. J. clin. Invest. 1960, 39, 765.

9. Mulrow, P. J., and W. F. Ganong. Stimulation of aldosterone secretion by angiotensin II. Yale J. Biol. Med. 1961, 33, 386.

10. Carpenter, C. C. J., J. O. Davis, and C. R. Ayers. Relation of renin, angiotensin II, and experimental renal hypertension to aldosterone secretion. $\mathrm{J}$. clin. Invest. 1961, 40, 2026.

11. Genest, J., W. Nowaczynski, E. Koiw, T. Sandor, and P. Biron. Adrenocortical function in essential hypertension in Essential Hypertension, K. D. Bock and P. T. Cottier, Eds. Berlin, SpringerVerlag, 1960, p. 126.

12. Laragh, J. H., S. Ulick, V. Januszewicz, Q. B. Deming, W. G. Kelly, and S. Lieberman. A1dosterone secretion and primary and malignant hypertension. J. clin. Invest. 1960, 39, 1091.

13. Davis, J. O., J. Urquhart, and J. T. Higgins, Jr. The effects of alterations of plasma sodium and potassium concentration on aldosterone secretion. J. clin. Invest. 1963, 42, 597.

14. Davis, J. O., C. C. J. Carpenter, C. R. Ayers, and R. C. Bahn. Relation of anterior pituitary function to aldosterone and corticosterone secretion in conscious dogs. Amer. J. Physiol. 1960, 199, 212.

15. Davis, J. O. Mechanisms regulating the secretion and metabolism of aldosterone in experimental secondary hyperaldosteronism. Recent Progr. Hormone Res. 1961, 17, 293.
16. Davis, J. O., C. C. J. Carpenter, C. R. Ayers, J. E. Holman, and R. C. Bahn. Evidence for secretion of an aldosterone-stimulating hormone by the kidney. J. clin. Invest. 1961, 40, 684.

17. Ganong, W. F., and P. J. Mulrow. Evidence of secretion of an aldosterone-stimulating substance by the kidney. Nature (Lond.) 1961, 190, 1115.

18. Davis, J. O., C. R. Ayers, and C. C. J. Carpenter. Renal origin of an aldosterone-stimulating hormone in dogs with thoracic caval constriction and in sodium-depleted dogs. J. clin. Invest. 1961, 40, 1466.

19. Farrell, G. Glomerulotropic activity of an acetone extract of pineal tissue. Endocrinology 1959, 65, 239.

20. Coghlan, J. P., D. A. Denton, J. R. Goding, and R. D. Wright. The control of aldosterone secretion. Postgrad. med. J. 1960, 36, 76.

21. Farrell, G. L. Discussion in J. O. Davis. Mechanisms regulating the secretion and metabolism of aldosterone in experimental secondary hyperaldosteronism. Recent Progr. Hormone Res. 1961, 17, 340.

22. Ganong, W. F., A. H. Lieberman, W. J. R. Daily, V. S. Yuen, P. J. Mulrow, J. A. Luetscher, Jr., and R. E. Bailey. Aldosterone secretion in dogs with hypothalamic lesions. Endocrinology 1959, 65, 18.

23. Newman, A. E., E. S. Redgate, and G. Farrell. The effects of diencephalic-mesencephalic lesions on aldosterone and hydrocortisone secretion. Endocrinology 1958, 63, 723.

24. Krieger, D. T., and I. H. Wagman. Hypothalamic lesions and adrenal function in the cat. Acta endocr. (Kbh.) 1961, 38, 88.

25. Blair-West, J., J. Coghlan, D. A. Denton, J. R. Goding, J. A. Munro, and R. D. Wright. The effect of neuraxial ablations upon the secretion of electrolyte-active steroid. J. Physiol. (Lond.) 1960, 153, 52P.

26. Denton, D. A. The study of sheep with permanent unilateral parotid fistulae. Quart. J. exp. Physiol. 1957, 42, 72.

27. Denton, D. A., and J. R. Sabine. The selective appetite for $\mathrm{Na}^{+}$shown by $\mathrm{Na}^{+}$-deficient sheep. $\mathrm{J}$. Physiol. (Lond.) 1961, 157, 97.

28. Peterson, R. E. The use of radio-isotopes in steroid methodology in Lipids and the Steroid Hormones in Clinical Medicine, F. W. Sunderman and F. W. Sunderman, Jr., Eds. Philadelphia, Lippincott, 1960, p. 141.

29. Blair-West, J. R., J. P. Coghlan, D. A. Denton, J. R. Goding, and R. D. Wright. The effect of aldosterone, cortisol, and corticosterone upon the sodium and potassium content of sheep's parotid saliva. J. clin. Invest. 1963, 42, 484.

30. Denton, D. A., J. R. Goding, and R. D. Wright. In Clinical Endocrinology, E. B. Astwood, Ed. New York, Grune \& Stratton, 1960, vol. 1, p. 373. 
31. Brobeck, J. R. Regulation of energy exchange in Medical Physiology and Biophysics, T. C. Ruch and J. F. Fulton, Eds. Philadelphia, W. B. Saunders, 1960, p. 1001.

32. Hemingway, A. Shivering. Physiol. Rev. 1963, 43, 397.

33. Moruzzi, G. Synchronizing influences on the brain stem and the inhibitory mechanisms underlying the production of sleep by sensory stimulation. The Moscow Colloquium on Electro-encephalography of Higher Nervous Activity. Electro-encephalography and Clinical Neurophysiology 1960, suppl. 13, 231.

34. Clynes, M. Unidirectional rate sensitivity: a biocybernetic law of reflex and humoral systems as physiologic channels of control and communication. Ann. N. Y. Acad. Sci. 1961, 92, 946.

35. Clynes, M. The non-linear biological dynamics of unidirectional rate sensitivity illustrated by analog computer analysis, pupillary reflex to light and sound, and heart rate behavior. Ann. N. Y. Acad. Sci. 1962, 98, 806.

36. Ganong, W. F., P. J. Mulrow, A. Boryczka, and G. Cera. Evidence for a direct effect of angiotensin-II on adrenal cortex of the dog. Proc. Soc. exp. Biol. (N. Y.) 1962, 109, 381.

37. Davis, J. O. Discussion in J. R. Blair-West, J. P. Coghlan, D. A. Denton, J. R. Goding, M. Win- tour, and R. D. Wright. The control of aldosterone secretion. Recent Progr. Hormone Res. $1963,19,311$.

38. Denton, D. A. Discussion in J. O. Davis. Mechanisms regulating the secretion and metabolism of aldosterone in experimental secondary hyperaldosteronism. Recent Progr. Hormone Res. 1961, 17, 331.

39. Blair-West, J. R., and J. R. Goding. Effect of temporary thoracic caval constriction on aldosterone secretion in conscious and in anaesthetized sheep. Endocrinology 1962, 70, 822.

40. Gross, F., D. Regoli, and G. Schaechtelin. Renal content and blood concentration of renin. Mem. Soc. Endocr. 1963, in press.

41. Gould, A. B., and L. T. Skeggs, Jr. The presence of renin in arteries. Fed. Proc. 1963, 22, 421.

42. Bartter, F. C., I. H. Mills, E. G. Biglieri, and C. Delea. Studies on the control and physiologic action of aldosterone. Recent Progr. Hormone Res. 1959, 15, 311.

43. Slater, J. D. H. Discussion in J. R. Blair-West, J. P. Coghlan, D. A. Denton, J. R. Goding, M. Wintour, and R. D. Wright. The control of aldosterone secretion. Recent Progr. Hormone Res. 1963, 19, 311.

44. Farrell, G. Regulation of aldosterone secretion. Physiol. Rev. 1958, 38, 709. 